\title{
Effects of wave loads on the strength of semisubmersible drilling platform
}

\author{
Fei Wang* and Xiong Deng** \\ * School of Mechatronic Engineering, Southwest Petroleum University, Chengdu, China \\ ** College of Petroleum Engineering, Southwest Petroleum University, Chengdu, China \\ *Corresponding Author : wangfei_swpu@126.com
}

Submitted : 31/07/2019

Revised : 21/09/2019

Accepted : 30/03/2020

\begin{abstract}
In order to reduce the failure risk of the structures of semisubmersible drilling platform during its service life, this research studies the effects of ocean wave loads on the strength of the platform's structures. The response spectra of the platform obtained from model test in wave tank were used to verify the accuracy of the numerical model employed in this research. Eight wave load cases, which may affect the strength of the platform but not involved in the classification societies such as ABS and DNV, were newly considered in this research. The results of the research indicate that a) four of the eight newly added wave load cases are found to be greatly affecting the strength of the platform and need to be considered in designing the structures; b) torsional moment and shearing force caused by the ocean wave would cause the stress of the structures of platform at a high level and need to be carefully evaluated.
\end{abstract}

Keywords: Wave loads; Semisubmersible drilling platform; Strength performance; Platform design.

\section{INTRODUCTION}

Semisubmersible Drilling platform (SEMI) is a large structure with facilities to house workers and machinery needed, to drill wells in the ocean bed, to extract oil and/or natural gas, to process fluids, and to ship or pipe them to shore. A destruction accident of SEMI may bring high risk of environment pollutions and casualties of operators as well as the economic losses, when the SEMI encounters extreme sea state (Almar et al., 1984; Moan, 2009; Zaron et al., 2015). The problems of making sure that the structure is safe have become the most important task of platform designers and operators. The strength of the platform's structures, therefore, needs to be carefully evaluated in the processes of SEMI designing to assure the structure safety over the duration of its service life.

Among all the components of a SEMI, structures that function as supporting structures in SEMI and bear complex loads, such as the linking structures and brace structures, are the critical elements. In fact, many destruction accidents occurred in the history indicated that the failures of a SEMI often initiated at these critical elements and cause the whole platform to fail to work or even sink after these structures were damaged (Colin et al., 2014). Take the accident of Alexander Keilland platform as an example; the loads were transferred to the other brace structures and led them break because of the overload due to the initial fracture of a horizontal brace. The failure of the brace 
structures then led to the failure of platform's column that caused the whole platform to sink and the death of 123 operators (Almar et al., 1984; Ersland et al., 1989). In designing a SEMI platform, therefore, it is crucial to evaluate the strength of SEMI's supporting structures and take appropriate actions to reduce the failure risk of these critical elements under environment loads, especially the wave induced hydrodynamic loads, which are the most important environment loads applying on the platform directly.

Many research works can be found in the literature on the strength studies of SEMI structures. Almost all of them focused their research on the strengths of the whole platform under environment loads (Soylemez 1995; Zhang et al., 2004; Nallayarasu et al., 2012; Rik et al., 2015). Qian et al. (2002) presented the strength of a semisubmersible platform under characteristic wave loads of vertical bending moment, torsion moment, and horizontal split force. $\mathrm{Li}$ et al. (2009) compared the different rules established by ABS and DNV classification society after calculating the wave loads of a SEMI by the deterministic design wave method and the stochastic design wave method. Jian et al. (2015) studied the wave drift forces of a semisubmersible platform under heading wave and beam wave by experimental test and numerical calculation. Based on the archived documents available to the authors, very few research works are found investigating the effects of wave loads on the strength of SEMI's supporting structures, though the importance of the structures is recognized by the researchers and engineers. Besides, the effects of wave loads on the strength of SEMI's supporting structures are not specified by the classification societies such as American Bureau of Shipping (ABS, 2014) and Det Norske Veritas (DNV, 2005), who provide standards and guidance for SEMI design in practice. As to the standards of the classification societies, 7 typical wave loads are considered for guiding the entire SEMI design. Nevertheless, the other types of wave loads may also affect the strength of SEMI and worth to be investigated. Fei et al. (2017) evaluated the effects of wave loads on the strength of SEMI's horizontal brace and found other 3 wave loads where classification societies are not involved in, which affect the strength of the brace structures.

The present research aims at investigating the strength of the supporting structures of a SEMI platform subjected to the hydrodynamic loads generated by various types of wave loads of the ocean. A finite element analysis model of the SEMI is to be established for quantitatively analyzing the strength related factors such as stresses and deformations of the structures under the wave loads. The wave types that are not included in the widely used standards but significantly affecting the strength of the supporting structures are to be identified with the implementation of the model, and to be suggested for brace structure design in practice. It is anticipated that the results of this research may enhance the efforts of the researchers and engineers in designing safer and more reliable supporting structures of SEMI, and therefore, safer and more reliable SEMI platforms.

\section{MODEL DEVELOPMENT FOR ANALYSIS}

\subsection{Structure Model of the Platform}

Different kinds of SEMIs appear with ocean engineering development, and structures of SEMI including the main deck, columns, pontoons, and brace structures have changed a lot. A typical SEMI of new generation, which is suitable for drilling operations worldwide and is actually in use, is selected for analyzing the effects of wave loads on the strength of the SEMI's structures. Shown as in Figure 1, the selected SEMI features one main deck, two large parallel pontoons, four groups of columns, and four horizontal braces. The geometrical dimensions of the main components of the SEMI are tabulated in Table 1. 


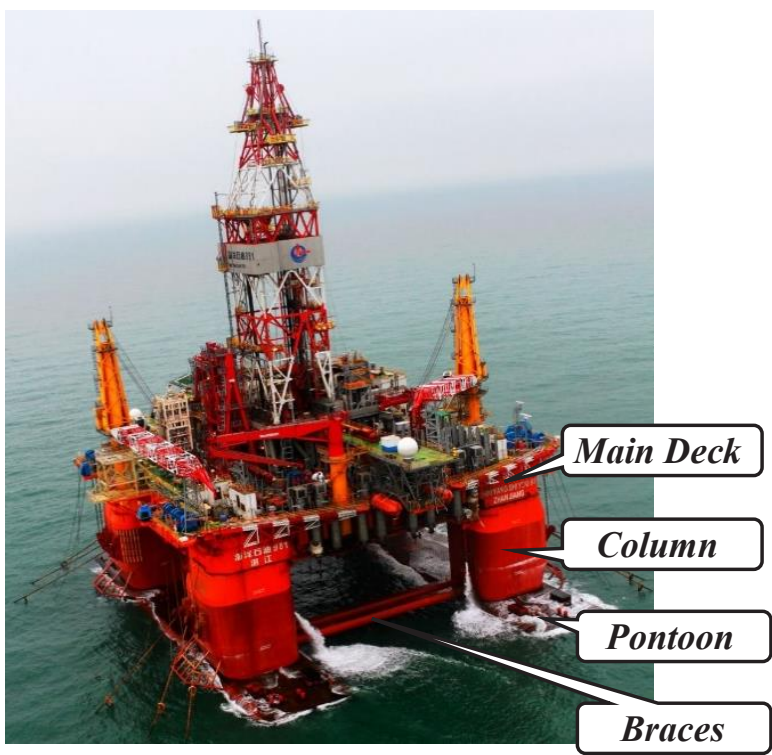

Figure 1. Selected semisubmersible platform for analysis.

Table 1. Main geometrical dimensions of the platform (unit: $\mathrm{m}$ ).

\begin{tabular}{|l|c|}
\hline \multicolumn{1}{|c|}{ Description } & Dimension \\
\hline Geometrical Dimension of Pontoon & $114.07 \times 20.12 \times 8.54$ \\
\hline Geometrical Dimension of Column & $17.4 \times 17.4 \times 21.4$ \\
\hline Geometrical Dimension of Main Deck & $114.4 \times 74.4 \times 38.6$ \\
\hline Geometrical Dimension of Horizontal brace & $\Phi 2.4 \times 42.7$ \\
\hline Distance between Main Deck & 58.6 \\
\hline Distance between Columns in Longitudinal Direction & 58.6 \\
\hline Distance between Columns in Transverse Direction & 58.6 \\
\hline Platform's draft in Operation Condition & 19 \\
\hline Platform's draft in Survival Condition & 16 \\
\hline Center of Gravity Position in Operation Condition & $(-0.13,0,19.5)$ \\
\hline Center of Gravity Position in Survival Condition & $(-0.14,0,24.4)$ \\
\hline Center of Buoyancy Position in Operation Condition & $(-0.13,0,6.7)$ \\
\hline Center of Buoyancy Position in Survival Condition & $(-0.14,0,5.9)$ \\
\hline
\end{tabular}


The structure model of the selected platform could hardly be established the same as the real platform, as the real platform is extremely complex. For the sake of clarification and efficiency of calculation, the model established makes some simplifications with considerations of the main components: deck, columns, pontoons, and braces, shown as in Figure 2. As the necessary equipment on the platform, such as drilling system, riser system, drilling derrick, drilling pipes, cranes, electricity equipment, and living facilities are relatively small in size, and the ocean waves do not apply on them directly, the equipment is considered as mass pieces located in their actual positions.

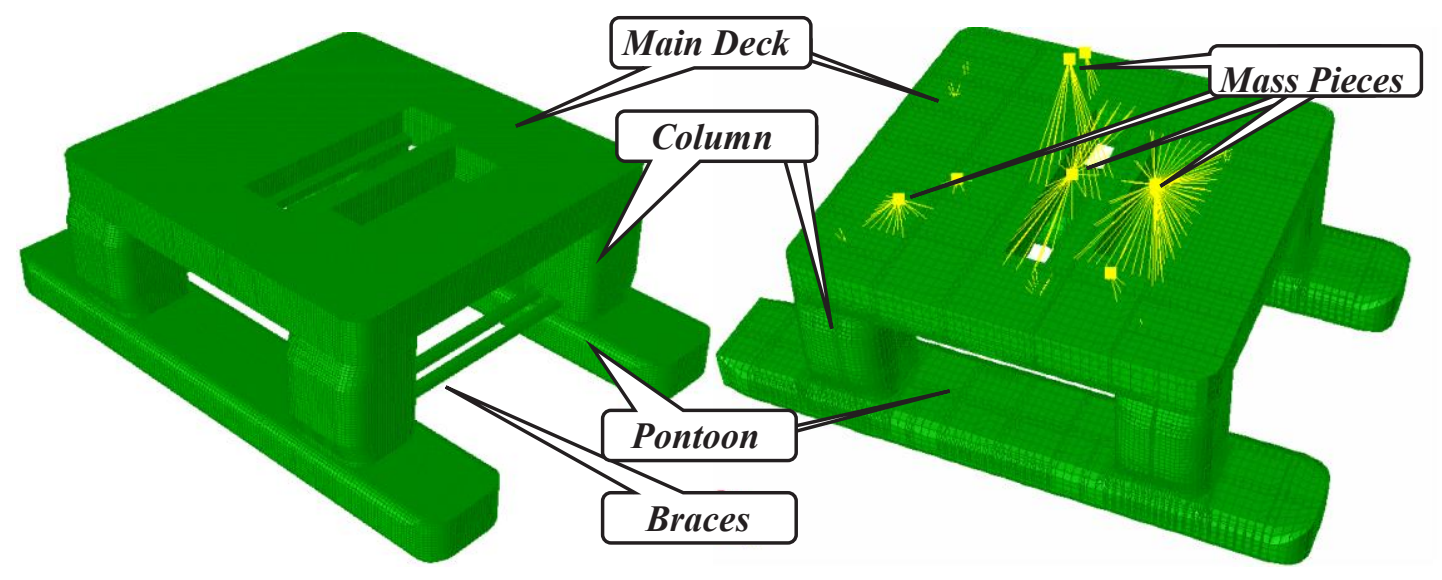

Figure 2. Structure model of the selected platform for analysis.

The structures of the platform are constructed following ABS guides using the fundamental elements such as beam and shell elements. The independence test has been conducted with four-grid system, and approximately 12 million grids were employed in the simulation. The total weight of the established model is 33,649 tons, allowing $2.4 \%$ of error compared with the actual platform selected. Besides, the errors of moment of inertia of the components considered in the modeling and the platform are controlled in less than $4 \%$ in comparison to the actual platform, as shown in Table 2.

Table 2. Moments of inertia of the components and platform.

\begin{tabular}{|c|c|c|c|c|}
\hline Component & Moments of inertia & Actual SEMI platform & Analysis model & Errors \\
\hline \multirow{3}{*}{ Main Deck } & $I z$ & $6971 \mathrm{~m}^{4}$ & $6719.12 \mathrm{~m}^{4}$ & $3.6 \%$ \\
\cline { 2 - 5 } & $I y$ & $102.6 \mathrm{~m}^{4}$ & $98.45 \mathrm{~m}^{4}$ & $4.0 \%$ \\
\hline \multirow{3}{*}{ Column } & $I z$ & $62.8 \mathrm{~m}^{4}$ & $60.3 \mathrm{~m}^{4}$ & $3.9 \%$ \\
\cline { 2 - 5 } & $I y$ & $70.5 \mathrm{~m}^{4}$ & $68.5 \mathrm{~m}^{4}$ & $2.8 \%$ \\
\hline \multirow{3}{*}{ Pontoon } & $I z$ & $82.9 \mathrm{~m}^{4}$ & $85.46 \mathrm{~m}^{4}$ & $3.1 \%$ \\
\cline { 2 - 5 } & $I y$ & $24.3 \mathrm{~m}^{4}$ & $23.34 \mathrm{~m}^{4}$ & $3.9 \%$ \\
\hline \multirow{3}{*}{ Platform } & $I z$ & $4.31 \times 10^{10} \mathrm{~m}^{4}$ & $4.21 \times 10^{10} \mathrm{~m}^{4}$ & $2.3 \%$ \\
\cline { 2 - 5 } & $I y$ & $4.69 \times 10^{10} \mathrm{~m}^{4}$ & $4.51 \times 10^{10} \mathrm{~m}^{4}$ & $3.8 \%$ \\
\cline { 2 - 5 } & $I z$ & $5.21 \times 10^{10} \mathrm{~m}^{4}$ & $5.09 \times 10^{10} \mathrm{~m}^{4}$ & $2.3 \%$ \\
\hline
\end{tabular}


In order to eliminate the rigid movement of the platform when the platform is loaded hydrodynamic loads, the established model is constrained by the three nodes below the parallel pontoons, shown in Figure 3. The three nodes selected have relatively smaller displacements and deformations compared with those of the other places in the platform. Node $A_{1}$ is constrained in $x, y$ and $z$ directions (marked blue, green, and red, respectively); node $A_{2}$ is constrained in $y$ and $z$ directions; and node $A_{3}$ is constrained in the vertical or $z$ direction.

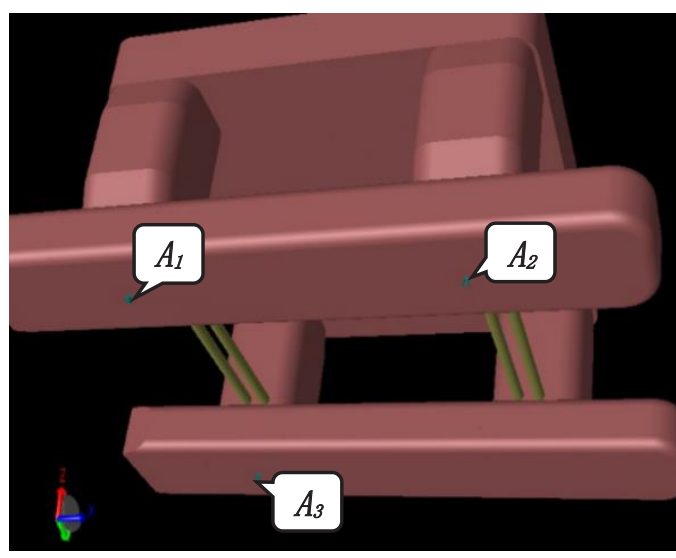

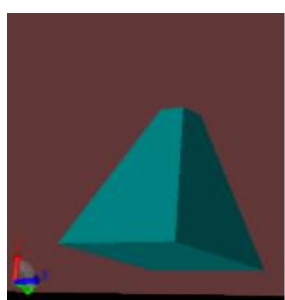

Node $A_{1}$

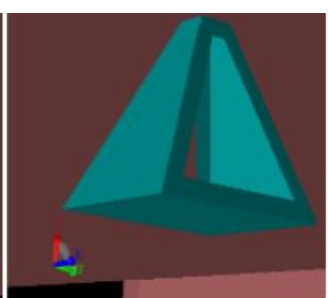

Node $A_{2}$

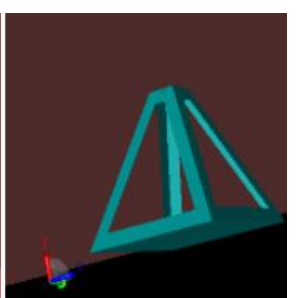

Node $A_{3}$

Figure 3. Boundary conditions for the global structure model.

\subsection{Hydrodynamic Model of the Platform}

Ocean waves are loaded on the pontoons, columns, and horizontal braces of the platform during its service life. To determine the strength performances of the platform under wave loads, two theories are adapted in this research for the responses of the ocean structures under wave loads varying from the features of the structure.

The wave radiation and diffraction forces are considered the main wave loads applied on the large-scale structures of the platform such as pontoons and columns. Then, the three-dimensional potential flow theory (Patrick et al., 1990; Richard 1998; Ibrahim et al., 2015), in which the potential of space velocity is divided into incidence potential, diffraction potential, and radiation potential to obtain pressure distribution, is used to calculate the wave force loading on the pontoons and columns. Meanwhile, the viscous effect becomes significant, while the diffraction effect is usually negligible when calculating the wave loading on the small-scale structures. Then, the Morison equation is used to evaluate the wave force loading on the horizontal braces.

In constructing the hydrodynamic model of the platform, shown in Figure 4, two types of model named panel model (based on the three-dimensional potential flow theory) and Morison model (based on the Morison equation) are implemented for calculating the forces created by the wave loads. 


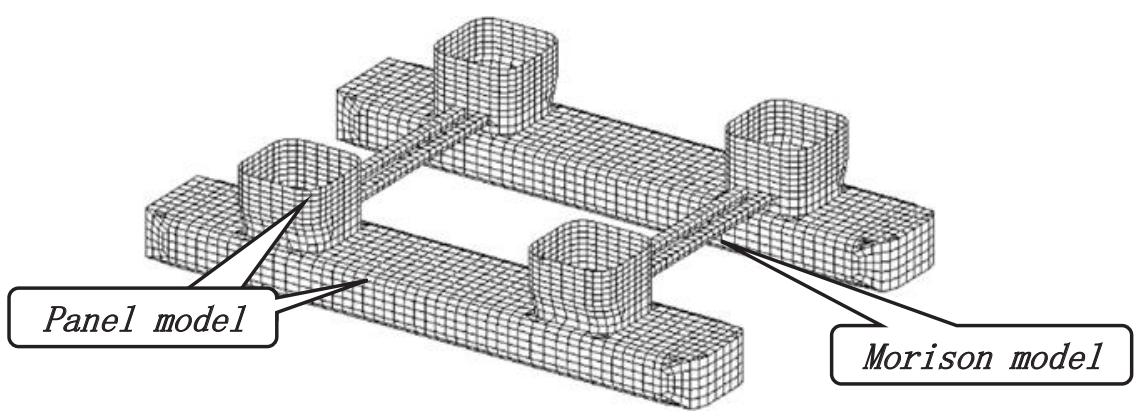

Figure 4. Hydrodynamic model of the platform.

\subsection{Verification of the Platform Model}

The displacement of the platform is the expected response under wave loads during its service life. In order to verify accuracy of the FE model established in this paper, the comparison between the displacement responses, which is numerically calculated by the FE model, and the displacement response, which is obtained by the model test tank (shown in Figure 5), was given in this paper.

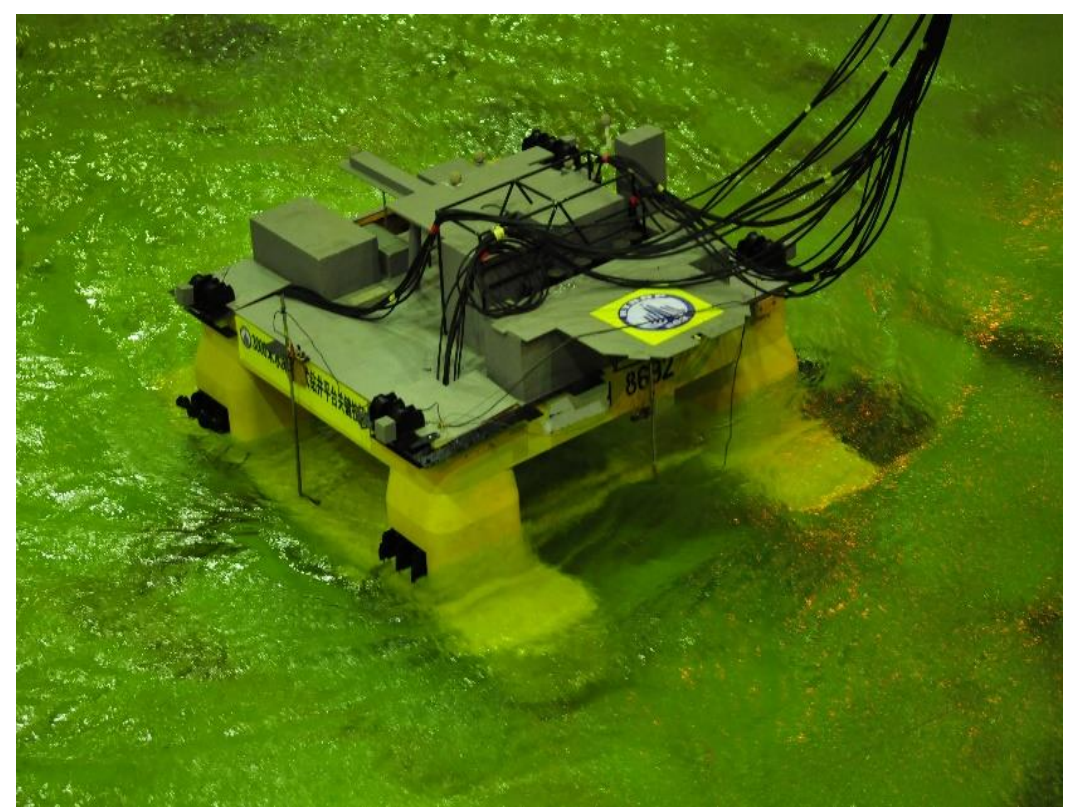

Figure 5. Response test in the wave tank.

As shown in Figure 6 and Figure 7, the response spectra of surge, heave, and pitch under heading wave and response spectra of surge, heave, and roll under beam wave are obtained. According to the response spectra comparison of the platform, the numerical calculation given in this paper coincides well with model test obtained by the model test tank, and the errors between them are less than 5\%. Therefore, the accurate response of the platform calculated by the FE model presented in this paper indicates that the wave loads could be given accurately too. 

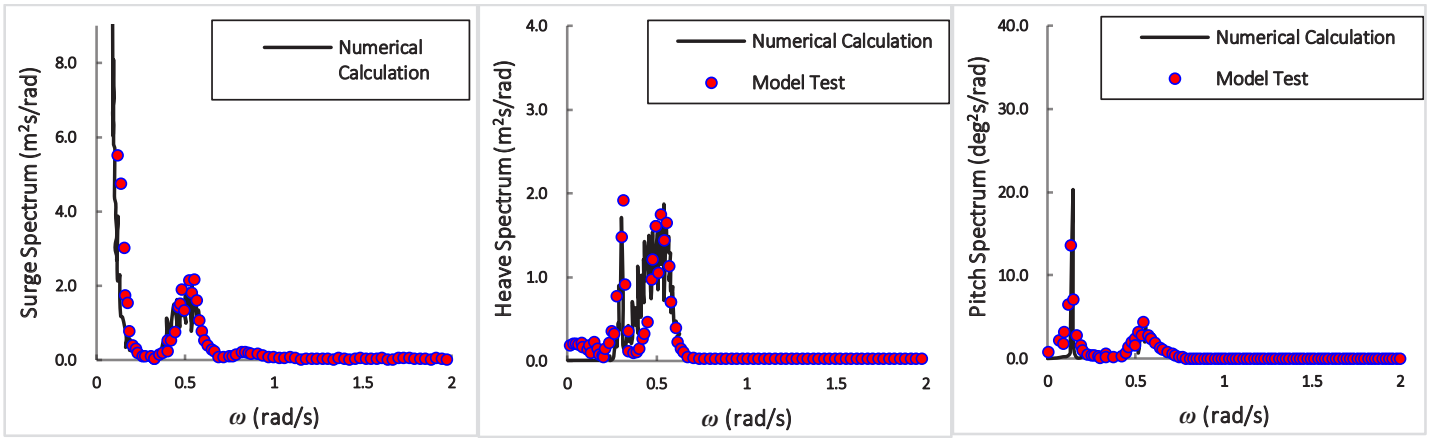

Figure 6. Response spectra of surge, heave, and pitch under heading wave.
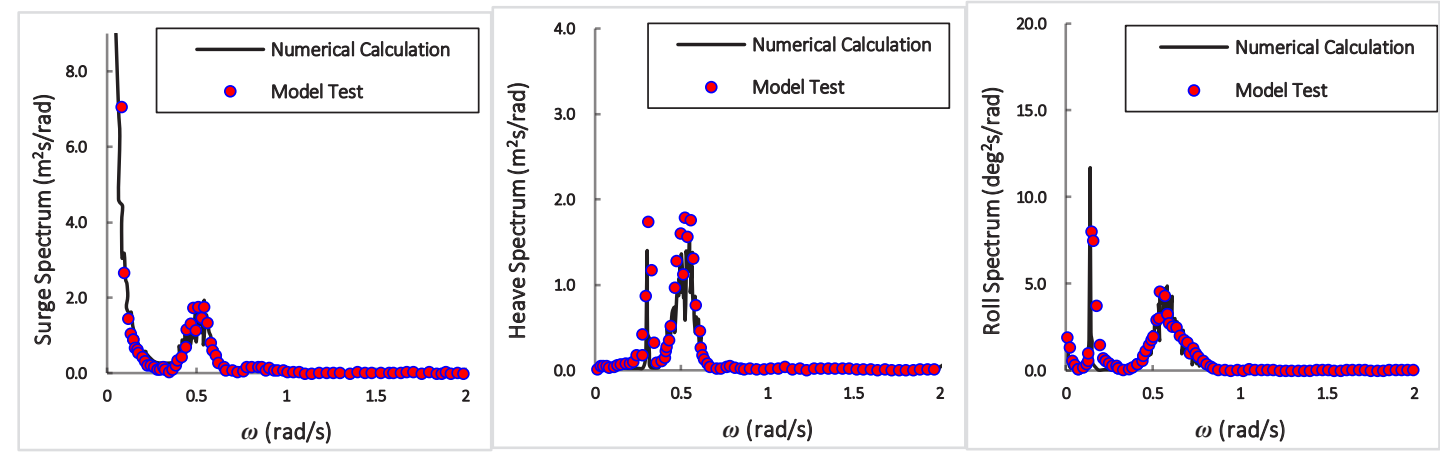

Figure 7. Response spectra of surge, heave, and roll under beam wave.

\section{ANALYSIS OF WAVE LOADS ON THE PLATFORM}

\subsection{Wave Conditions}

As the stern and aft of the platform are exactly symmetrical, as well as the starboard and port of the platform, shown in Figure 8, the wave directions are assumed to vary from 0 degree to 90 degrees with an increment of 15 degrees in performing the numerical analyses. Meanwhile, the wave frequency is considered as varying from 0.1 $\mathrm{rad} / \mathrm{s}$ to $1.5 \mathrm{rad} / \mathrm{s}$, to reflect the actual wave frequencies most commonly seeing in the ocean areas, and an increment of $0.05 \mathrm{rad} / \mathrm{s}$ is used in the numerical simulations. 


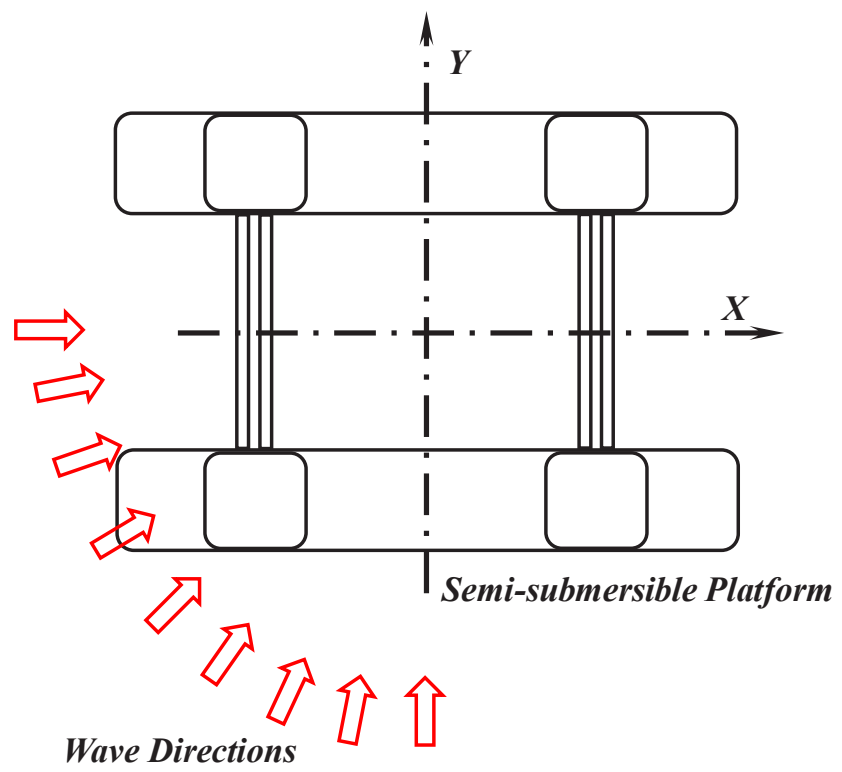

Figure 8. Directions of the ocean wave.

Furthermore, the JONSWAP spectrum (Lewis et al., 1990) is used to specify the random ocean waves in South China Sea. Both the operation condition and survival condition of the platform are considered in this research. The environmental parameters used in the numerical analyses are listed in Table 3, in reflecting the extreme ocean conditions in South China Sea (Chu et al., 2004; Zhifeng et al., 2014).

Table 3. Environmental parameters for extreme ocean conditions.

\begin{tabular}{|c|c|c|}
\hline Environment parameters & Operation condition & Survival condition \\
\hline significant wave height (m) & 6.0 & 13.3 \\
\hline spectral peak period (s) & 11.2 & 15.5 \\
\hline spectral peak enhancement factor & 2.4 & 2.4 \\
\hline wind velocity (m/s) & 23.1 & 55.0 \\
\hline surface ocean current velocity (m/s) & 0.93 & 1.97 \\
\hline draft of the platform (m) & 19 & 16 \\
\hline
\end{tabular}

As shown in Table 4, the wave scatter of the South China Sea, which provides a joint probability table of significant wave height $(H s)$ and mean zero crossing period $(T z)$, is used for statistically forecasting the wave loads (Kohei et al., 1998; Peter et al., 2008; Zhifeng et al., 2014). 
Table 4. Wave scatter of South China Sea.

\begin{tabular}{|c|c|c|c|c|c|c|c|c|}
\hline $\boldsymbol{H} \boldsymbol{T}$ & $<=\mathbf{3}$ & $\mathbf{3} \mathbf{4}$ & $\mathbf{4 \sim 5}$ & $\mathbf{5 \sim 6}$ & $\mathbf{6 \sim 7}$ & $\mathbf{7 \sim 8}$ & $\mathbf{8} \mathbf{9}$ & $\mathbf{9 \sim 1 0}$ \\
\hline $\mathbf{0 . 0} \mathbf{0 . 5}$ & 0.597 & 2.536 & 4.395 & 1.719 & 0.269 & 0 & 0 & 0 \\
\hline $\mathbf{0 . 5} \mathbf{1 . 0}$ & 0.778 & 6.51 & 6.853 & 6.671 & 2.739 & 0.089 & 0 & 0 \\
\hline $\mathbf{1 . 0} \mathbf{1 . 5}$ & 0.045 & 3.704 & 8.26 & 5.814 & 4.434 & 0.09 & 0 & 0 \\
\hline $\mathbf{1 . 5} \mathbf{2 . 0}$ & 0 & 0.275 & 7.591 & 5.332 & 3.283 & 0.497 & 0 & 0 \\
\hline $\mathbf{2 . 0} \mathbf{2 . 5}$ & 0 & 0 & 2.798 & 4.388 & 2.93 & 0.451 & 0.09 & 0 \\
\hline $\mathbf{2 . 5} \mathbf{3 . 0}$ & 0 & 0 & 0.273 & 3.547 & 1.714 & 0.629 & 0.045 & 0 \\
\hline $\mathbf{3 . 0} \mathbf{3 . 5}$ & 0 & 0 & 0.046 & 1.692 & 1.623 & 0.672 & 0.093 & 0 \\
\hline $\mathbf{3 . 5} \mathbf{4 . 0}$ & 0 & 0 & 0 & 0.453 & 2.209 & 0.987 & 0 & 0 \\
\hline $\mathbf{4 . 0} \mathbf{4 . 5}$ & 0 & 0 & 0 & 0 & 0.494 & 0.448 & 0 & 0 \\
\hline $\mathbf{4 . 5} \mathbf{5 . 0}$ & 0 & 0 & 0 & 0 & 0.134 & 0.36 & 0.045 & 0 \\
\hline $\mathbf{5 . 0} \mathbf{6 . 0}$ & 0 & 0 & 0 & 0 & 0.367 & 0.448 & 0.045 & 0 \\
\hline
\end{tabular}

\subsection{Wave Load Cases}

The wave-induced loads on the platform considered in this research are splitting forces, twisting pitch moment, shear forces, bending moments, and inertia forces induced by accelerations of platform mass. The high stresses of the platform often exist at the connections of the structures failures usually occurring at these parts of the platform first, such as in the accidents of Alexander Keilland platform (Almar et al., 1984). Therefore, additional wave induced loads other than those considered by ABS and DNV are considered in this research to reflect the harsh wave loads that may apply to the platform, shown in Table 5.

Additionally, the auxiliary sections of the platform need to be considered for the analysis and determination of the wave loads. Six auxiliary sections of the platform, including the cross middle section and the longitudinal middle section where the rules of ABS and DNV are determined, are taken into consideration in this research, shown in Figure 9. 
Table 5. Wave loads cases considered in the research.

\begin{tabular}{|l|l|l|}
\hline Load Cases & Wave loads & Remarks \\
\hline Load Case 01 & Splitting force in longitudinal middle section & ABS, DNV \\
\hline Load Case 02 & Torsional moment in longitudinal middle section & ABS, DNV \\
\hline Load Case 03 & Longitudinal shear force in longitudinal middle section & ABS, DNV \\
\hline Load Case 04 & Vertical bending moment in cross middle section & ABS, DNV \\
\hline Load Case 05 & Transverse initial load of unit mass & ABS, DNV \\
\hline Load Case 06 & Longitudinal initial load of unit mass & ABS, DNV \\
\hline Load Case 07 & Vertical acceleration & DNV \\
\hline Load Case 08 & Vertical bending moment in longitudinal middle section & Newly added \\
\hline Load Case 09 & Vertical shear force in longitudinal middle section & Newly added \\
\hline Load Case 10 & Torsional moment in cross middle section & Newly added \\
\hline Load Case 11 & Vertical shear force in cross middle section & Newly added \\
\hline Load Case 12 & Torsional moment in longitudinal section of the starboard connection structure & Newly added \\
\hline Load Case 13 & Torsional moment in longitudinal section of the port side connection structure & Newly added \\
\hline Load Case 14 & Torsional moment in cross section of the stern connection structure & Newly added \\
\hline Load Case 15 & Torsional moment in cross section of the aft connection structure & Newly added \\
\hline
\end{tabular}

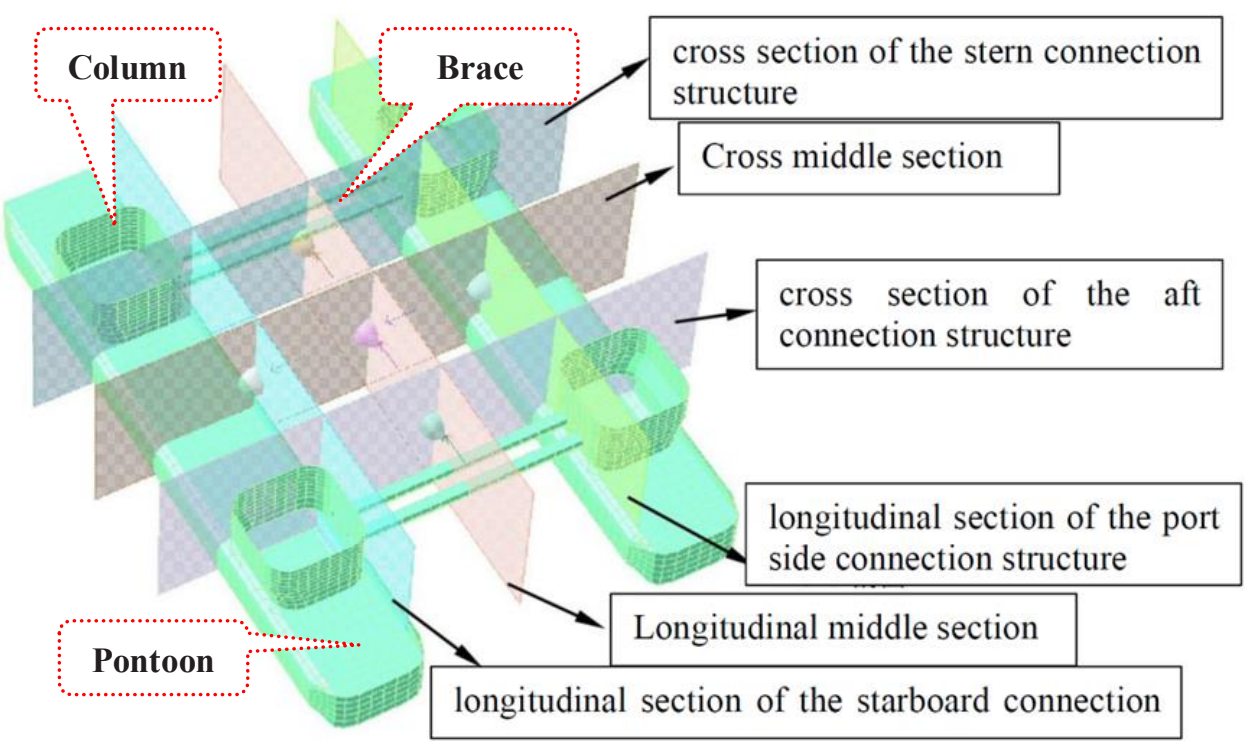

Figure 9. Auxiliary sections of the platform for wave load cases. 


\subsection{Design Waves of Each Load Cases}

Design wave is an equivalent regular wave characterized by an amplitude, frequency, heading, and wave crest position relative to the platform. By loading each typical wave load case's design wave on the platform, designers could obtain the maximum stress distribution of the platform under each load case and take some precautions during the initial design period.
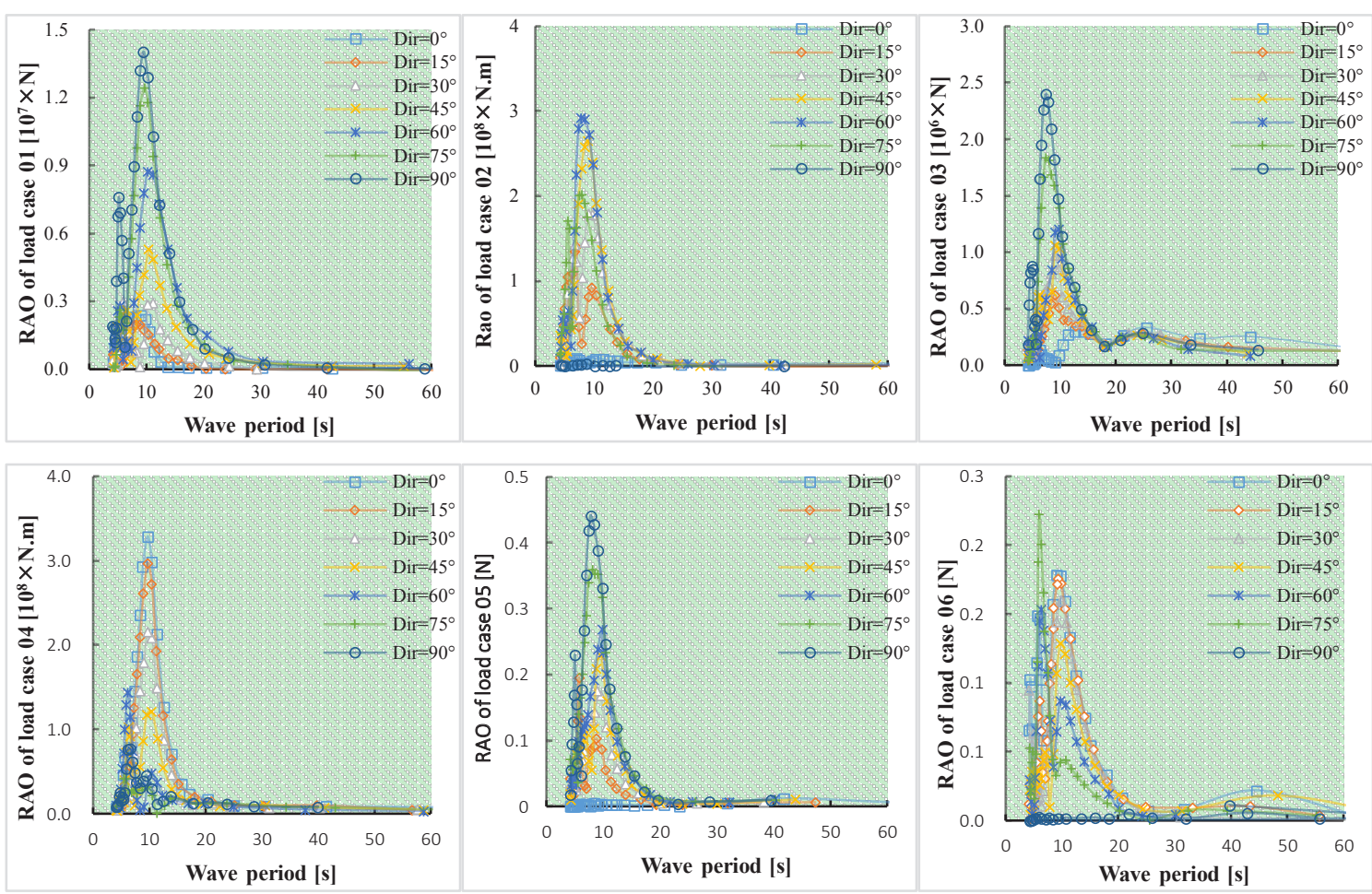

Figure 10. RAO of wave loads (from Load Case 01 to Load Case 06).

According to the calculated response amplitude operator (RAO) of each wave load case, obtained by searching ranges of wave periods and wave headings, the frequencies and headings of design waves of each load case could be easily determined. The RAO of the first six load cases is shown in Figure 10. Take wave load case 01 as an example; the platform would encounter maximum splitting force, $1.4 \times 10^{7} \mathrm{~N}$, when the platform encounters ocean wave with wave period of $9.5 \mathrm{~s}$ and wave direction of 90 degrees.

The platform would encounter kinds of ocean wave conditions during its service life. The long-term predictions of the wave loads, which can be regarded as the combination of infinite short-term response, are considered in this research. According to the long-term response (LTR) of each wave load case, obtained by searching ranges of wave appearance probabilities and wave headings, the scale parameter and slope parameter of long-term statistical forecasting of the wave loads could be determined by using the wave scatter (shown as in Table 4). The LTR of the first six load cases is shown in Figure 11. 

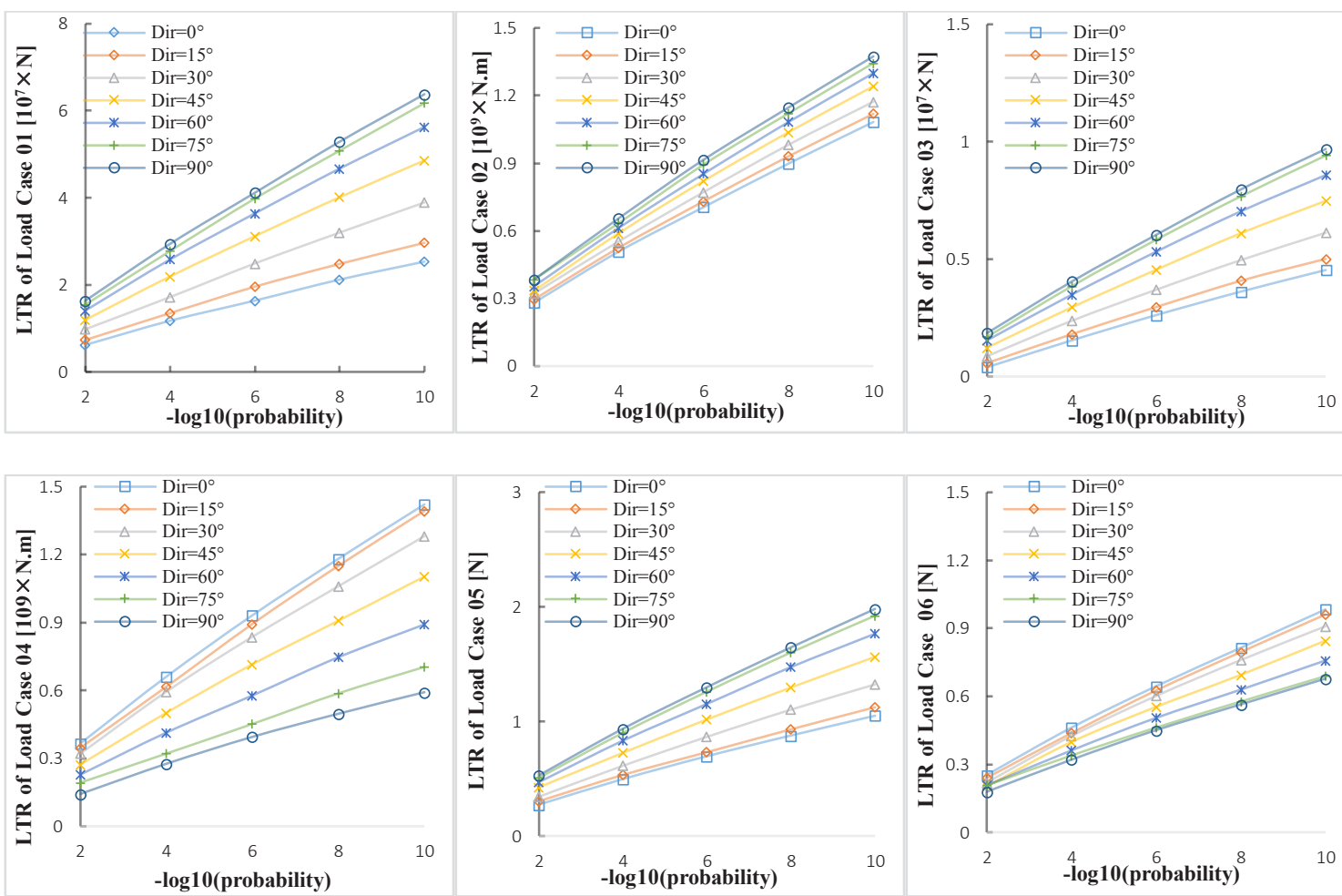

Figure 11. LTR of wave loads (from Load Case 01 to Load Case 06).

Table 6. Design wave parameters of the wave loads.

\begin{tabular}{|l|l|l|l|l|l|l|l|l|l|l|}
\hline \multirow{2}{*}{$\begin{array}{c}\text { Calculation } \\
\text { Cases }\end{array}$} & \multicolumn{2}{|c|}{$\begin{array}{c}\text { Direction } \\
{\left[{ }^{\circ} \text { ] }\right.}\end{array}$} & \multicolumn{2}{c|}{$\begin{array}{c}\text { Frequency } \\
{[\mathbf{r a d} / \mathbf{s}]}\end{array}$} & \multicolumn{3}{c|}{$\begin{array}{c}\text { Phase } \\
{\left[{ }^{\circ}\right]}\end{array}$} & \multicolumn{2}{c|}{$\begin{array}{c}\text { Amplitude } \\
{[\mathbf{m}]}\end{array}$} & \multicolumn{2}{c|}{$\begin{array}{c}\text { Length } \\
{[\mathbf{m}]}\end{array}$} \\
\cline { 2 - 12 } & OC & SC & OC & SC & OC & SC & OC & SC & OC & \multicolumn{1}{|c|}{ SC } \\
\hline Load Case 01 & 90 & 90 & 0.67 & 0.67 & -30.04 & -33.75 & 4.4 & 4.4 & 137.19 & 137.19 \\
\hline Load Case 02 & 60 & 60 & 0.79 & 0.79 & 173.87 & 163.48 & 4.2 & 4.29 & 98.68 & 98.68 \\
\hline Load Case 03 & 45 & 45 & 0.63 & 0.63 & 9.65 & -13.12 & 4.5 & 4.67 & 155.17 & 155.17 \\
\hline Load Case 04 & 0 & 0 & 0.66 & 0.63 & 141.58 & 141.67 & 4.2 & 4.26 & 141.38 & 155.17 \\
\hline Load Case 05 & 90 & 90 & 0.78 & 0.78 & -94.88 & -101.31 & 4.2 & 4.33 & 101.23 & 101.23 \\
\hline Load Case 06 & 75 & 75 & 1.05 & 1.05 & -90.22 & -101.94 & 3.4 & 3.01 & 55.86 & 55.86 \\
\hline Load Case 07 & 90 & 90 & 0.97 & 0.97 & -6.37 & -15.22 & 3.9 & 3.23 & 65.45 & 65.45 \\
\hline Load Case 08 & 90 & 90 & 0.66 & 0.66 & -27.19 & -29.93 & 4.3 & 4.37 & 141.38 & 141.38 \\
\hline Load Case 09 & 90 & 90 & 0.84 & 0.84 & 80.59 & 73.38 & 3.8 & 3.89 & 87.28 & 87.28 \\
\hline Load Case 10 & 45 & 45 & 0.69 & 1.14 & -10.98 & -65.37 & 4.5 & 4.69 & 129.36 & 47.389 \\
\hline Load Case 11 & 0 & 0 & 0.89 & 0.89 & 68.86 & 46.54 & 2.7 & 2.62 & 77.75 & 77.75 \\
\hline Load Case 12 & 60 & 60 & 0.79 & 0.79 & 179.38 & 169.29 & 4.2 & 4.26 & 98.68 & 98.68 \\
\hline Load Case 13 & 60 & 60 & 0.74 & 0.78 & 165.39 & 157.23 & 4.4 & 4.41 & 112.47 & 101.23 \\
\hline Load Case 14 & 45 & 45 & 0.74 & 0.69 & 15.00 & 10.14 & 3.7 & 3.64 & 112.47 & 129.36 \\
\hline Load Case 15 & 45 & 45 & 0.74 & 0.69 & -164.05 & -168.12 & 3.6 & 3.65 & 112.47 & 129.36 \\
\hline
\end{tabular}


Then, parameters of design waves of each wave load case are determined according to the RAO and LTR of each load case by adapting the long-term response method, shown in Table 6. According to the obtained design waves of each wave load case, directions of ocean wave which dominate the strength of SEMI's horizontal brace most are all same both in operation condition (OC) and survival condition (SC). Moreover, different wave load cases might occur under same wave direction, such as Load Case 01, Load Case 05, Load Case 07, Load Case 08, and Load Case 09. In addition, it can be found that different wave load cases would appear in different wave conditions. Take wave load case 01 and wave load case 03 as example; the maximum splitting force (Load Case 01) appears when the platform encounters the transverse wave (wave direction is 90 degrees) and the wavelength approaches the double width of the platform. However, the maximum Longitudinal shear force (Load Case 03) appears when the platform encounters the oblique wave (wave direction is 45 degrees) and the wavelength approaches the 1.5 times diagonal length of the platform.

\subsection{Load Responses of Structures}

As shown in Figure 12, structures of the platform would have different deformations when the platform encounters different wave loads. Take the deformation of the braces as an example; the brace structure deformed a lot when the platform encounters oblique ocean wave (load case 02 , load case 03 , load case 12, and load case 13), while the deformation of the brace can be ignored when the platform encounters heading wave and beam wave. Therefore, it would be necessary to evaluate the effects of each wave load case on the strength performance of each structures of the platform.
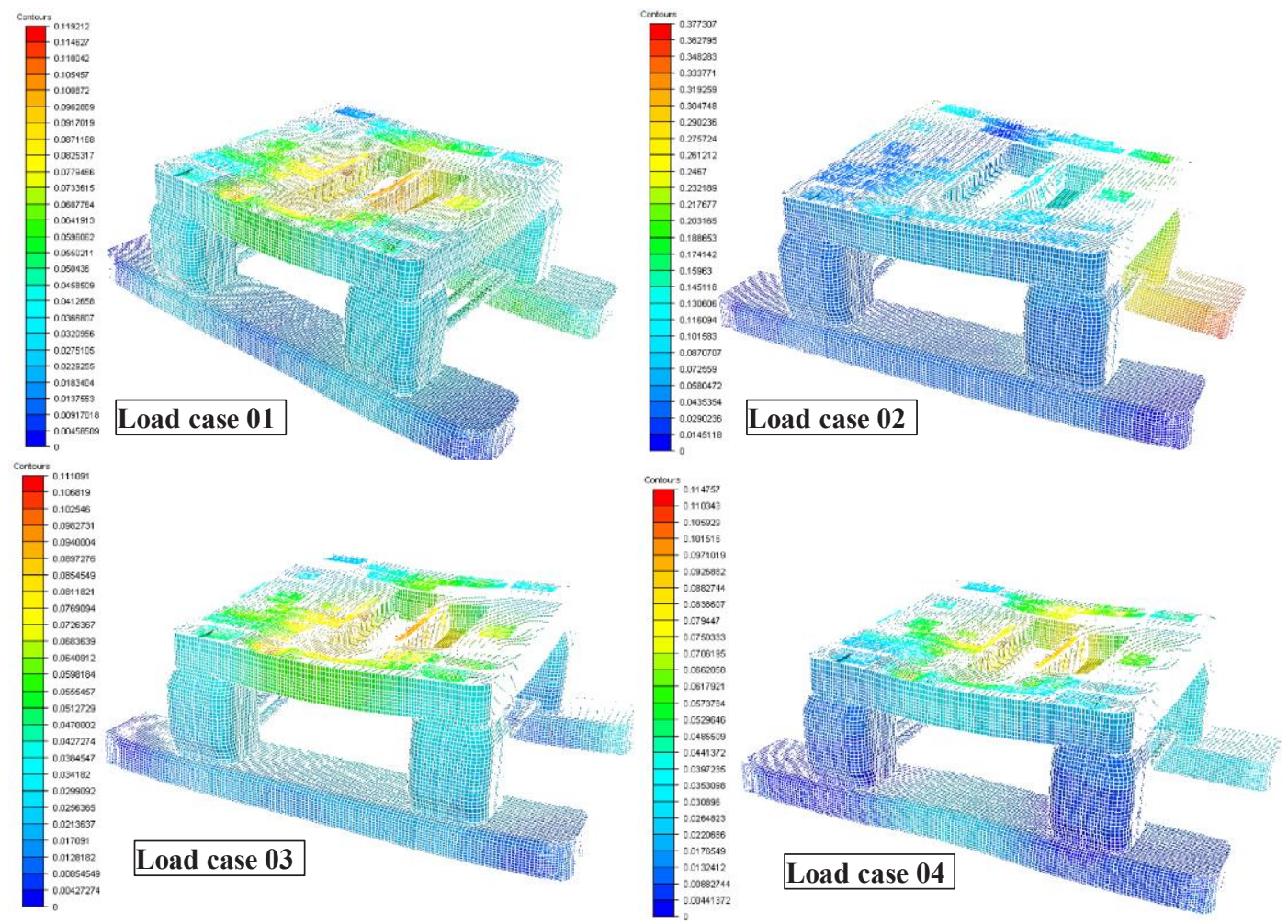

Figure 12. Deformations of the platform (from Load Case 01 to Load Case 04). 
According to the evaluation of the wave load cases on the strength performances of the platform, the stress of the structures is well distributed. Moreover, the maximum stresses of each structure are located at the connection parts of the platform, shown in Figure 13. More attention, therefore, should be paid to the connection areas, where the maximum stress of the platform exists, during the design and analysis of the platform.

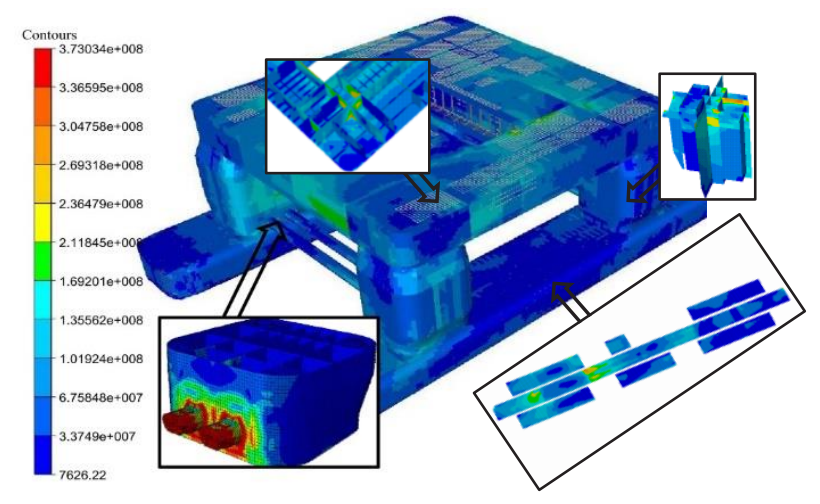

Figure 13. Stress distributions of the platform.

As shown in Figure 14, the value of the maximum stresses of each structure of the platform varies with the wave load cases. The maximum stress of brace structure would be much higher when the platform encounters wave load case 12 and wave load case 13, in which this research is newly added rather than that those classification societies suggested, shown in Figure 14 (a). Similarly, the maximum stresses of the column, pontoon, and deck would be much higher when the platform encounters wave load case 12, wave load case 14, and wave load case 15, shown in Figures 14 (b), (c), and (d). Besides the load calculation of characteristic wave load cases, in which the rules (such as ABS and DNV) are involved, it would be better, therefore, to evaluate the effects of the wave load cases of torsional moment in load case 12, load case 13, load case 14, and load case 15 on the platform during analyzing the wave loads on each structures. Moreover, it is necessary to add these 4 load cases into rules to make the structure strength of each structures of the platform stay at a safe range.
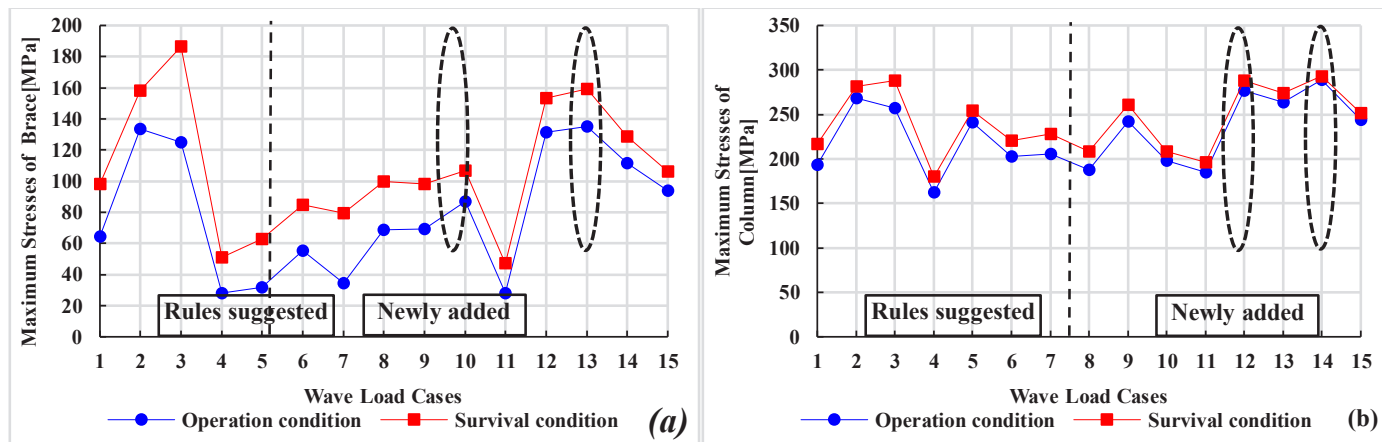

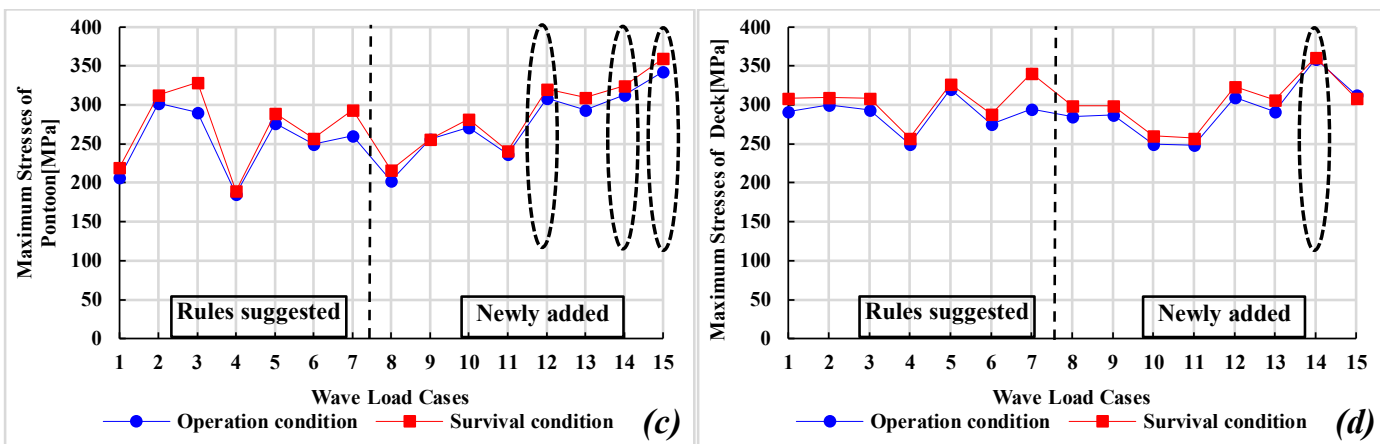

Figure 14. Maximum stresses of each structures under wave load cases.

Additionally, the torsional moment and shearing force caused by the ocean wave, generated by the wave load case 02 , wave load case 03, and wave load cases from 12 to 15 considered in this research shown as in Figure 14, would cause the stress of the structures of platform at a high level. And it would be much safer to adjust the heading direction of the platform to avoid high stress appearing at the structures if the platform encounters horrible sea state, in which the ocean wave is similar to the design wave of these wave loads mentioned above.

\section{CONCLUSION}

This research investigates the effects of 15 types wave loads, including the loads the classification societies involved and those that might dominate the strength of the platform, on the strength of the main structures of semisubmersible drilling platform. Based on the work done in this article, the following results and conclusions can be drawn:

(1) The accuracy of the numerical model employed in this article has been verified based on the displacement responses of the platform. The response spectra of the platform obtained from the employed model are in good agreement with those obtained from model test in wave tank. The numerical model established in this article, therefore, could accurately calculate the loads generated by the ocean wave.

(2) The design wave parameters of the considered wave loads under both condition and survival condition have been analyzed based on the calculated RAO and LTR of each wave load case. The results indicate that (1) the wave directions are all the same in these two conditions under the same wave loads; (2) the wave directions may be different or remain the same under different wave loads.

(3) The four torsional moment wave loads out of the eight newly added wave loads in this article are found to be greatly affecting the strength of the structures compared with those suggested by classification societies.

(4) The torsional moment and shearing force caused by the ocean wave are the main loads dominating the effects of the loads on the strength of structures of the platform.

In order to decrease the high stress on the platform's structures and make sure that the structure strength is within the safe range, it would be necessary to add the calculation of the newly added wave loads in this article when analyzing the strength of structures during the design period of the platform. 


\section{ACKNOWLEDGMENT}

The authors would like to acknowledge the support by scientific research starting project of SWPU (No. 2017QHZ010), China.

\section{REFERENCE}

Almar N., Haagensen P., and Moan T. 1984. Investigation of the Alexander L. Kielland Failure-Metallurgical and Fracture Analysis, Journal of Energy Resources and Technology. 106(1): 24-30.

ABS. 2014. Rules for Building and Classing Mobile Offshore Drilling Unites.

Chu C., Qi Y., Chen Y., Shi P., and Mao Q. 2004. South China Sea Wind-Wave Characteristics. Part I: Validation of Wavewatch-III Using TOPEX/Poseidon Data. Journal of Atmospheric and Oceanic Technology. 21(11): 1718-1733.

Colin H., Espen F., and Martyn T. 2014. Worldwide Offshore Accident Databank, Det Norske Veritas, Oslo.

DNV. 2005. DNV -RP -C103: Column Stabilized Units.

Ersland S., Weisaeth L., and Sund A. 1989. The Stress upon Rescuers Involved in an Oil Rig Disaster - Alexander L. Kielland 1980. Acta Psychiatrica Scandinavica. 80: 38-39.

Fei W., Liming Dai., and Zheng L. 2017. Effects of Wave Loads on the Horizontal Bracing Strength of a Semisubmersible Platform. Proceedings of the Institution of Civil Engineers-Maritime Engineering. 170(1):21-31.

Fei W., and Zheng L. 2017. Load Assessment on the Horizontal Braces of Semi-submersible Drilling Platform under Ocean Wave. Arabian Journal for Science and Engineering. 42(11): 4789-4799.

Ibrahim C., and Onder E. 2015. Progress in Clean Energy-Volume I: Analysis and Modeling. Springer Vienna Publishers.

Jian H ., and Li Z. 2015 Experimental and Numerical Study on Wave Drift Forces on a Semi-Submersible Platform in Waves. Ships and Offshore Structures: 1-10.

Lewis W., and Allos N. 1990. JONSWAP's parameters: Sorting out the inconsistencies. Ocean Engineering. 17(4):409-415.

Li H.; Ren H.; Wei T.; Feng G.: Study on the Wave Loads and Strength Assessment Method in SemiSubmersible Platform. Proceedings of the ASME 2009 28th International Conference on Ocean, Offshore and Arctic Engineering, Honolulu, 31May-5June, 2009.

Kohei N., Shinji K., and Daoxuan Q. 1998. Wave Characteristic on the Central Coast of Vietnam in the South China Sea. Coastal Engineering Journal. 40(4): 347-366.

Ming F., Chih F., and Chun W. 2007. Prediction of Design Wave Loads of the Ocean Structure by Equivalent Irregular Wave Approach. 34(10):1422-1430.

Moan T. 2009. Development of Accidental Collapse Limit State for Offshore Structures. Structure Safety. 31(2): 124-135.

Nallayarasu S., and Prasad P. 2012. Hydrodynamic Response of Spar and Semi-Submersible Interlinked by A Rigid Yoke-Part I: Regular Waves. Ships and Offshore Structures. 7(3):297-309.

Patrick K., and Ronald L. 1990. Three Dimensional Potential Flows from Functions of a 3D Complex Variable. Fluid Dynamics Research. 6(3):119-137.

Peter C., and Kuofeng C. 2008. South China Sea Wave Characteristics during Typhoon Muifa Passage in Winter 2004. Journal of Oceanography. 64(1):1-21. 
Qian K.; Wang Y.: Wave Load Calculation of Structural Analysis for a Semi-Submersible Platform. Proceeding of the Twelfth International Offshore and Polar Engineering Conference, Kitakyushu. 26-31 May 2002.

Qiao D., and Ou J. 2013. Global Response Analysis of A Semi-Submersible Platform with Different Mooring Model in South China Sea. Ships and Offshore Structures. 8(5):441-456.

Richard J. 1998. The handbook of Fluid Dynamics. Springer Vienna Publishers.

Rik W., Roel L., Arthur V., and Tim B. 2015. Numerical Simulation of Hydrodynamic Wave Loading by a Compressible Two-Phase Flow Method. Computers and Fluids, 114, 218-231.

Soylemez M. 1995. Motion Test of a Twin-Hulled Semi-Submersible. Ocean Engineering, 22(6):643-660.

Thanh T., and Dong K. 2015. The Coupled Dynamic Response Computation for A Semi-Submersible Platform of Floating Offshore Wind Turbine. Journal of Wind Engineering and Industrial Aerodynamics, 147: 104119.

Xuejun W., Zhiping C., Jinlu K., and Hai G. 2014. Assessment on Semi-submersible Drilling Unit with Fatigue Cracks. Offshore Technology Conference-Asia, Malaysia: 1-10.

Zaron E., Fitzpatrick P., and Patrick J. 2015. Initial evaluations of a Gulf of Mexico/Caribbean ocean forecast system in the context of the Deep-water Horizontal disaster. Frontiers of Earth Science. 9(4): 605-636.

Zhang H., Ren H., Dai Y., and Fei G. 2004. Wave Load Computation in Direct Strength Analysis of SemiSubmersible Platform Structures. Journal of Marine Science and Application. 3(1): 7-13.

Zhifeng W., Liangming Z., Sheng D., Lunyu W., Zhanbin L., Lin M., and Aifang W. 2014. Wind Wave Characteristics and Engineering Environment of the South China Sea. Journal of Ocean University of China. 13(6):893-900. 